\title{
Osteokinematic analysis during shoulder abduction using the C-arm
}

\author{
Seung Hoo Lee ${ }^{a}$, Younghoon Kim ${ }^{b}$, Dong Geon Lee ${ }^{a}$, Kyeong-Bong Lee ${ }^{c}$, Gyu Chang Lee ${ }^{d}$ \\ ${ }^{a}$ Department of Physical Therapy, Graduate School of Kyungnam University, Changwon, Republic of Korea \\ ${ }^{\mathrm{b}}$ Kim Institute, Lancaster, CA, USA \\ 'Physical Therapy Part, Department of Physical and Rehabilitation Medicine, Samsung Medical Center, Seoul, Republic of Korea \\ ${ }^{\mathrm{d}}$ Department of Physical Therapy, Kyungnam University, Changwon, Republic of Korea
}

Objective: Despite reliable evidence of abnormal scapular motions increases, there is not yet sufficient evidence of abnormal humeral translations. This study aims to analyze the motion of the humeral head toward the scapula when the shoulder is actively abducted using the $\mathrm{C}$-arm.

Design: A case report.

Methods: The participant was a healthy man without any limitation and pain during shoulder movement. The participant's shoulder was abducted; this movement in the frontal plane was measured using a C-arm (anterior-posterior view) and was analyzed with computer-aided design. The starting posture was $15^{\circ}$, and as the participant abducted his shoulder measurements were taken and analyzed at $30^{\circ}, 60^{\circ}, 90^{\circ}, 120^{\circ}, 150^{\circ}$, and ending at $165^{\circ}$. A line was drawn perpendicularly to the line connecting the humeral head axis to the glenoid, and another line was drawn perpendiculary to the line connecting the scapular axis to the glenoid. The distance between the two lines measured is defined as the e value.

Results: At the starting posture $\left(15^{\circ}\right)$, the central axis of the humeral head was located $1.92 \mathrm{~mm}$ inferior to the central axis of the scapula. The humeral head was superiorly translated from the starting posture to $120^{\circ}$, and then, showed an inferior translation to the ending posture $\left(165^{\circ}\right)$.

Conclusions: The results of this study showed that the humeral head moved upward from the starting posture $\left(15^{\circ}\right)$ up to $120^{\circ}$ indicating, superior translation, and it moved downward when the posture was past $120^{\circ}$, indicating inferior translation.

Key Words: C-arm, Kinematic analysis, Shoulder abduction

\section{Introduction}

Generally, $34 \%$ of the population complains of shoulder pain more than once in a lifetime [1], and its prevalence is $20.9 \%$, placing it as the second common impairment in the musculoskeletal system [2]. In addition, shoulder dysfunction is continuous and repetitive [3]. An important key to shoulder function is the rotator cuff [4]. In addition, for the stabilization of the humeral head toward the glenoid during shoulder abduction, normal function of the rotator cuff is necessary [5,6]. Rotator cuff injury affects $30 \%$ to $40 \%$ of the population over the age of 60 years and has a significant impact on medical expenses [7]. Repairs for rotator cuff injury continue to increase, and physical therapy for this is important $[8,9]$. In addition, assessment of pain after the repair using a pain scale, such as the visual analog scale and range of motion (ROM) is important [10]. Self-exercise, joint mobilization and continuous passive movement are often used to enhance ROM [11].

For joint mobilization, physical therapists often use the concepts of Kaltenborn, Maitland, and Mulligan [12]. Kaltenborn and Evjenth [13] proposed joint mobilization ac-

Received: 26 September, 2017 Revised: 19 November, 2017 Accepted: 26 November, 2017

Corresponding author: Gyu Chang Lee

Department of Physical Therapy, Kyungnam University, 7 Gyeongnamdaehak-ro, Masanhappo-gu, Changwon 51767, Republic of Korea Tel: 82-55-249-2739 Fax: 82-55-999-2173 E-mail: leegc76@kyungnam.ac.kr

(a) This is an Open-Access article distributed under the terms of the Creative Commons Attribution Non-Commercial License (http://creativecommons.org/licenses/ by-nc/4.0) which permits unrestricted non-commercial use, distribution, and reproduction in any medium, provided the original work is properly cited.

Copyright @ 2017 Korean Academy of Physical Therapy Rehabilitation Science 
cording to the convex-concave rule on glide. The convex-concave rule is considered a critical theory in physical therapists' treatment decision-making [14]. The humeral head (convex) glides in the opposite direction when it moves to the glenoid (concave). This refers to the inferior glide of the humeral head in shoulder abduction [15]. Joint mobilization is an approach that makes a motion in the reduced direction to restore the normal movement, and the direction of the glide is determined considering the shape of the joint surface [15]. However, a recent study raises a question about this principle [16]. A previous study of a cadaver noted that $40 \%$ of the fibular joint surface of tibiofibular joints was plane; $57 \%$ convex and concave; and $3 \%$ convex [17]. This study shows the difficulty in the application of the convex-concave rule according to the joint surface [16]. In addition, a study of the joint translation noted that superior translation of the humeral head occurred (average $2 \mathrm{~mm}$ ) in shoulder abduction [18]. Nishinaka et al. [19] reported that in shoulder abduction from $0^{\circ}$ to $80^{\circ}$, the humeral head moved upward of approximately $1.7 \mathrm{~mm}$ and that from $80^{\circ}$ to $150^{\circ}$, the humeral head moved upward of less than $1 \mathrm{~mm}$. In addition, Graichen et al. [20] reported that in shoulder abduction from $30^{\circ}$ to $120^{\circ}$, there was a superior translation of the humeral head. In shoulder abduction from $120^{\circ}$ to $150^{\circ}$, there was an inferior translation of the humeral head.

In addition, a dispute over joint mobilization based on the controversial convex-concave rule is also in progress [16]. Kaltenborn's convex-concave rule is a familiar concept in joint treatment techniques and arthrokinematics. However, the weighting of the evidence according to the Elwood [21] classification and the agency for health care policy and research [22] classification guidelines indicated that the evidence was weak and limited. The indirect method, using Kaltenborn's convex-concave rule as applied to the glenohumeral joint, may need to be reconsidered [15].

Despite reliable evidence of abnormal scapular motions increases, there is not yet sufficient evidence of abnormal humeral translations [23-25]. Shoulder kinematics was analyzed using standard radiographs [4,5,26-28], magnetic resonance imaging (MRI) [29-32], ultrasound [33] and computed tomography (CT) [34]. Of the researchers, Poppen and Walker [5] defined the axis of the humerus and scapula using standard radiographs and analyzed the motion, accordingly. In most previous studies, images were shot in static positions, and dynamic glenohumeral arthrokinematics was not described [35]. In addition, because the two-dimensional (2D) radiographic approach was used in both of these studies, descriptions of humeral head translations were limited to static measures in the superior-inferior direction and were subject to possible projection errors [36]. It is difficult to measure dynamic humeral head translation, but the results of a 3D analysis during the clinical shoulder motion are beginning to be reported $[19,37,38]$. It seems that treatment and rehabilitation of shoulder injuries will be enhanced with better knowledge of glenohumeral mechanics during dynamic activities in healthy and pathologic joints [19]. The number of studies projecting the body's motion and analyzing joint motion using the C-arm (GE OEC 9800 plus; GE OEC Medical Systems Inc., Salt Lake City, UT, USA, 2012) that can move and shoot X-ray images continue to increase [39].

Thus, through this study, we visually recorded the movement of the humerus toward the scapula when the shoulder is abducted dynamically and consecutively. This study aims to analyze the motion of the humeral head toward the scapula when the shoulder is abducted actively using the $\mathrm{C}$-arm.

\section{Methods}

\section{Subjects}

This study recruited one healthy man through the bulletin board in Kyungnam University. The participant's characteristics were as follows: age, 28 years; height, $183 \mathrm{~cm}$; and weight, $85 \mathrm{~kg}$. The participant who did not have any pain in the shoulder joint, did not have a history of any injury on the muscles around the joint and the skeleton, and could perform shoulder abduction within normal ROM was selected. Persons who had congenital disorders in the shoulder joint or surrounding muscles and skeleton, those who had side effects (vomiting, diarrhea or dizziness) in an X-ray exam, those who had adhesive capsulitis, degenerative arthritis and active inflammatory disease were excluded. The participant joined voluntarily and signed an agreement to participate. This study was conducted after the approval of Kyungnam University Ethics Commission (IRB No. 1040460-A-2016011).

\section{Measure}

The $\mathrm{C}$-arm used in this study was $1,024 \times 1,024$ pixels. The image processing speed was 16-bit, which can enlarge images from 9 to 12 inches. The measurement was taken in the anterior-posterior direction. The participant was asked to sit on a chair in an anatomical position, rotating $30^{\circ}$ from the $\mathrm{X}$-ray beam $\left(30^{\circ}\right.$ from the frontal plane). The $30^{\circ}$ rotation 
was to make the scapular plane and X-ray beam on a straight line. The shoulder was located at least within $2 \mathrm{~cm}$ from an image intensifier to minimize distortion. In order to minimize exposure to the X-ray, the participant was asked to wear a lead dress on the parts other than those used for the experiment. The height of the $\mathrm{C}$-arm was adjusted so that the entire ROM of the proximal axis of the shoulder joint and humerus was displayed. Then, the participant raised the arm sideways. A radiologist with five years of clinical experience had made these measurements. Beginning from the starting posture $\left(15^{\circ}\right)$, measurements were taken at intervals of $30^{\circ}, 60^{\circ}, 90^{\circ}, 120^{\circ}, 150^{\circ}$, and the ending posture $\left(165^{\circ}\right)$ as the participant abducted the shoulder. A line was drawn perpendicularly to the line connecting the humeral head axis to the glenoid, and another line was drawn perpendicularly to the line connecting the scapular axis to the glenoid. The distance measured between the two lines was defined as the e value. The measurements were taken dynamically and consecutively, and the results were saved in video and picture files, which could be observed later. The picture files were captured $\left(135^{\circ}\right)$, and a professional designer took these and conducted computer-aided design (CAD) work.

The standard definitions of the humeral translation and the angle of the humerus were based on Poppen and Walker [5] (Figure 1). In order to show anatomical characteristics, AutoCAD software (Autodesk Inc., San Rafael, CA, USA, 2014) was used, and an image-transforming operation was conducted by a designer with an 8-year experience in CAD. The designer was not aware of the contents of the study. The glenoid was described by drawing lines on the top and bottom edges of the glenoid, and the center was defined as the axis of the scapula (Os) (Figure 1; (a)). A circle was drawn around the humeral head, and the center was defined as the axis of the humeral head (Oh) (Figure 1; (b) [5]. Lines were drawn, respectively, perpendicular to the lines from the Os and $\mathrm{Oh}$ to the glenoid. The distance measured between the two lines was defined as the e value (Figure 1; (C) [5]. Variable e can be expressed by the glide of the humeral head toward the glenoid or the distance of the translations. At the center of the scapula, the center of the humeral head can move upward or downward [4]. Using this figure, the translations of the humeral head toward the glenoid were analyzed by the angle.

\section{Results}

The starting posture $\left(15^{\circ}\right)$ entailed having the participant

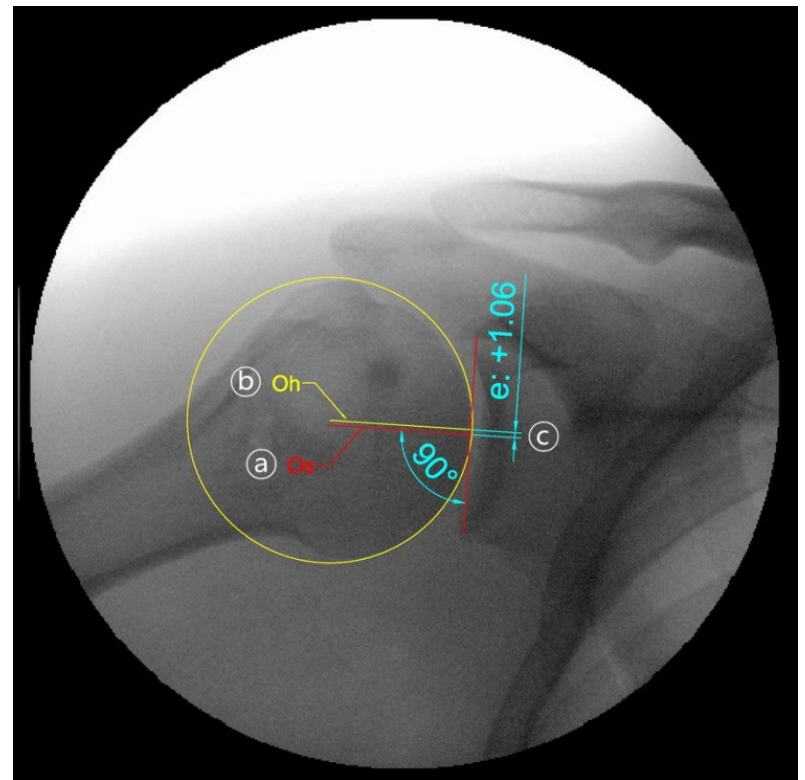

Figure 1. Radiographic analysis. a: axis of the scapula, b: axis of the humeral head (Oh), c: the e value.

sit comfortably in a chair in an anatomical position. At this angle, the central axis of the humeral head was located to be $1.92 \mathrm{~mm}$ lower than the central axis of the scapula (inferior). When the shoulder was abducted to $30^{\circ}$, the e value was +0.02 , and the humeral head was translated superiorly of $1.94 \mathrm{~mm}$ from the starting posture. When the shoulder was abducted from $30^{\circ}$ to $60^{\circ}$, the e value was +1.06 , and it the humeral head was translated superiorly of $1.04 \mathrm{~mm}$. When the shoulder was abducted from $60^{\circ}$ to $90^{\circ}$, the e value was +1.40 , and the humeral head was translated superiorly of $0.34 \mathrm{~mm}$. When the shoulder was abducted from $90^{\circ}$ to $120^{\circ}$, the e value was +1.87 , and it there was a superior translation of 0.47 $\mathrm{mm}$ of the humeral head. When the shoulder was abducted from $120^{\circ}$ to $150^{\circ}$, the e value was +0.30 , and the humeral head was inferiorly translated of $1.57 \mathrm{~mm}$. When the shoulder was abducted from $150^{\circ}$ to $165^{\circ}$, the e value was +0.20 , and the humeral head was inferiorly translated of $0.10 \mathrm{~mm}$. From the starting angle to $120^{\circ}$, the humeral head was superiorly translated relative to the scapula and then was translated inferiorly (Table 1).

\section{Discussion}

The motion of the humeral head at the shoulder joint surface was studied for the first time by Poppen and Walker [5]. This study defined the axis of the humeral head and the axis of the scapula, and it conducted static experimental research 
Table 1. Change in e value by angle

\begin{tabular}{lcc}
\hline \multicolumn{1}{c}{ Angle } & e value $(\mathrm{mm})$ & Translation $(\mathrm{mm})$ \\
\hline Start position $\left(15^{\circ}\right)$ & -1.92 & - \\
$30^{\circ}$ & +0.02 & 1.94 \\
$60^{\circ}$ & +1.06 & 1.04 \\
$90^{\circ}$ & +1.40 & 0.34 \\
$120^{\circ}$ & +1.87 & 0.47 \\
$150^{\circ}$ & +0.30 & 1.57 \\
End position $\left(165^{\circ}\right)$ & +0.20 & 0.10 \\
\hline
\end{tabular}

using X-ray [5]. Later studies, too, have depended on cadaveric simulations [18], 2D imaging [5], static 3D imaging [40-42] and conventional motion measurement systems [36]. Cadaveric experiments can provide accurate measures of joint position or motion, but are unable to duplicate the complex motions or forces associated with in vivo conditions [43]. The shoulder joint was experimented in 3D using MRI [41], CT [40], and biplane radiography [42], but currently, these technologies are limited to static analyses.

This study conducted serial radiography in shoulder abduction using the $\mathrm{C}$-arm that can conduct dynamic experiments, and followed the definitions of the axis of the humeral head and the axis of the scapula by Poppen and Walker [5]. In addition, the digital image was analyzed using CAD.

Bey et al. [43] found that when the shoulder was abducted, the humeral head was translated superiorly then inferiorly in both the repaired rotator cuff and the contralateral shoulder. The differences in the previously mentioned study is that it was conducted with a patient after supraspinatus surgery and static 3D imaging and biplane radiography were used; the patient was also holding a weight as the experiment was conducted. These findings were the same as the result of Graichen et al. [41] which was the inferior translation of the humeral head from $30^{\circ}$ to $150^{\circ}$. However, Graichen et al. [41] measured passive ROM, which is different from the measurement of active ROM in this study. Boyer et al. [37] reported on the superior translation of the humeral head from $0^{\circ}$ to $45^{\circ}$ and its inferior translation from $45^{\circ}$ to $90^{\circ}$ in a $3 \mathrm{D}$ evaluation of the humeral head motion.

According to Poppen and Walker [5] the humeral head was superiorly translated as the shoulder was abducted in both groups with and without a problem in the shoulder. A later study by Deutsch et al. [4] revealed significant findings of the superior translation of the humeral head in impingement syndrome.

In this study, the healthy participant actively abducted the shoulder, which was measured at every $30^{\circ}$. It was found that the humeral head moved upward from the starting posture $\left(15^{\circ}\right)$ up to $120^{\circ}$, indicating superior translation, and it moved downward when the posture was past $120^{\circ}$, indicating inferior translation. A previous study showed the same result of the humeral head moving upward from $30^{\circ}$ to $120^{\circ}$ and moving downward from $120^{\circ}$ to $150^{\circ}$ during shoulder abduction [20].

A study found that during active shoulder abduction, the superior translation of the humeral head from the inferior to the center of the glenoid is an average of $1.7 \mathrm{~mm}$ [19]. Another study found that the superior translation of the humeral head increases regardless of the angle [35]. Both studies investigated healthy participants without any shoulder disease. Chen et al. [26] also, investigated healthy participants. In the group before exercise, the superior translation of the humeral head moved in shoulder abduction from $0^{\circ}$ to $135^{\circ}$, but it was not significant. In the group after the exercise, the superior translation of the humeral head was discovered $(2.8 \mathrm{~mm})$ in shoulder abduction from $0^{\circ}$ to $90^{\circ}$, and inferior translation was discovered $(0.3 \mathrm{~mm})$ from $90^{\circ}$ to $135^{\circ}[26]$. A later study also found that the superior translation of the humeral head was discovered (average, 0.79 $\mathrm{mm}$ ) in shoulder abduction after the fatigue of the supraspinatus, infraspinatus, and teres minor muscles [35].

According to Schomacher [16] the reasoning model of the convex-concave rule is that the axis of motion should be considered stationary for simplification; however, it was reported that the rolling component in human joints shifts the axis. This report refutes the problem of the first approach to the convex-concave rule, as well as the problem in the setting of the direction of the joint motion. In addition, he argued that it is important to find the actual motion limitation and execute the joint mobilization rather than deciding the joint mobilization only from a pathological perspective [16]. In other words, if there is a limitation in shoulder abduction, it is important to find and execute the actual limitation direction of the glide, rather than executing the inferior glide of the humeral head without a test. Lazennec et al. [17] found that $55 \%$ of the tibial joint surface was plane; $40 \%$, convex; and $5 \%$, concave. This is an example that demonstrates how difficult it is to apply the convex-concave rule according to the surface of the joint [16]. Studies supporting this challenge have also concluded that superior translation of the humeral head occurs in shoulder abduction.

A limitation of this study is that it is a pilot study in which only one young, healthy man participated; therefore, it is difficult to generalize the results to other age groups, women, 
or people with shoulder dysfunction. Another limitation is that it did not measure direct humeral head translation within the joint, so it is difficult to understand the exact data values. It would be necessary to further conduct the study with more participants and investigate the actual motion by shooting with the scale, which is the basis in shooting with a $\mathrm{C}$-arm in the future. We believe that for shoulder kinematics, dynamic $\mathrm{C}$-arm measurement and analysis can provide important information to increase the understanding of shoulder function. In addition, it is judged that this information will lead to a better strategy for rehabilitation.

\section{Conflict of Interest}

The authors declared no potential conflicts of interest with respect to the authorship and/or publication of this article.

\section{References}

1. Green S, Buchbinder R, Glazier R, Forbes A. Interventions for shoulder pain. Cochrane Database Syst Rev 2000;2:CD001156.

2. Picavet HS, Schouten JS. Musculoskeletal pain in the Netherlands: prevalences, consequences and risk groups, the DMC(3)study. Pain 2003;102:167-78.

3. Winters JC, Jorritsma W, Groenier KH, Sobel JS, Meyboom-de Jong B, Arendzen HJ. Treatment of shoulder complaints in general practice: long term results of a randomised, single blind study comparing physiotherapy, manipulation, and corticosteroid injection. BMJ 1999;318:1395-6.

4. Deutsch A, Altchek DW, Schwartz E, Otis JC, Warren RF. Radiologic measurement of superior displacement of the humeral head in the impingement syndrome. J Shoulder Elbow Surg 1996;5:186-93.

5. Poppen NK, Walker PS. Normal and abnormal motion of the shoulder. J Bone Joint Surg Am 1976;58:195-201.

6. Poppen NK, Walker PS. Forces at the glenohumeral joint in abduction. Clin Orthop Relat Res 1978;(135):165-70.

7. Milgrom C, Schaffler M, Gilbert S, van Holsbeeck M. Rotatorcuff changes in asymptomatic adults. The effect of age, hand dominance and gender. J Bone Joint Surg Br 1995;77:296-8.

8. Osborne JD, Gowda AL, Wiater B, Wiater JM. Rotator cuff rehabilitation: current theories and practice. Phys Sportsmed 2016;44:85-92.

9. Sambandam SN, Khanna V, Gul A, Mounasamy V. Rotator cuff tears: an evidence based approach. World J Orthop 2015;6:90218.

10. Yi A, Villacis D, Yalamanchili R, Hatch GF 3rd. A comparison of rehabilitation methods after arthroscopic rotator cuff repair: a systematic review. Sports Health 2015;7:326-34.

11. Thomson S, Jukes C, Lewis J. Rehabilitation following surgical repair of the rotator cuff: a systematic review. Physiotherapy 2016;102:20-8.
12. Noten S, Meeus M, Stassijns G, Van Glabbeek F, Verborgt O, Struyf F. Efficacy of different types of mobilization techniques in patients with primary adhesive capsulitis of the shoulder: a systematic review. Arch Phys Med Rehabil 2016;97:815-25.

13. Kaltenborn FM, Evjenth O. Manual mobilization of the extremity joints: basic examination and treatment techniques. Oslo: O.N. Bokenhandel; 1989.

14. Kirby K, Showalter C, Cook C. Assessment of the importance of glenohumeral peripheral mechanics by practicing physiotherapists. Physiother Res Int 2007;12:136-46.

15. Brandt C, Sole G, Krause MW, Nel M. An evidence-based review on the validity of the Kaltenborn rule as applied to the glenohumeral joint. Man Ther 2007;12:3-11.

16. Schomacher J. The convex-concave rule and the lever law. Man Ther 2009; 14:579-82.

17. Lazennec JY, Besneard J, Cabanal J. L'articulation péronéo-tibiale supérieure une anatomie et une physiologie mal connues: quelques réflexions physiologiques et thérapeutiques. Annales de kinésithérapie 1994;21:1-5.

18. Harryman DT 2nd, Sidles JA, Clark JM, McQuade KJ, Gibb TD, Matsen FA 3rd. Translation of the humeral head on the glenoid with passive glenohumeral motion. J Bone Joint Surg Am 1990;72:1334-43.

19. Nishinaka N, Tsutsui H, Mihara K, Suzuki K, Makiuchi D, Kon $\mathrm{Y}$, et al. Determination of in vivo glenohumeral translation using fluoroscopy and shape-matching techniques. J Shoulder Elbow Surg 2008; 17:319-22.

20. Graichen H, Hinterwimmer S, von Eisenhart-Rothe R, Vogl T, Englmeier KH, Eckstein F. Effect of abducting and adducting muscle activity on glenohumeral translation, scapular kinematics and subacromial space width in vivo. J Biomech 2005;38: 755-60.

21. Elwood JM. Critical appraisal of epidemiological studies and clinical trials. Oxford: Oxford University Press; 2007.

22. Ejnisman B, Andreoli CV, Soares BG, Fallopa F, Peccin MS, Abdalla RJ, et al. Interventions for tears of the rotator cuff in adults. Cochrane Database Syst Rev 2004;1:CD002758.

23. Ludewig PM, Cook TM. Alterations in shoulder kinematics and associated muscle activity in people with symptoms of shoulder impingement. Phys Ther 2000;80:276-91.

24. Lukasiewicz AC, McClure P, Michener L, Pratt N, Sennett B. Comparison of 3-dimensional scapular position and orientation between subjects with and without shoulder impingement. J Orthop Sports Phys Ther 1999;29:574-83; discussion 584-6.

25. Warner JJ, Micheli LJ, Arslanian LE, Kennedy J, Kennedy R. Scapulothoracic motion in normal shoulders and shoulders with glenohumeral instability and impingement syndrome. A study using Moiré topographic analysis. Clin Orthop Relat Res 1992; (285):191-9.

26. Chen SK, Simonian PT, Wickiewicz TL, Otis JC, Warren RF. Radiographic evaluation of glenohumeral kinematics: a muscle fatigue model. J Shoulder Elbow Surg 1999;8:49-52.

27. Rossi F, Ternamian PJ, Cerciello G, Walch G. Posterosuperior glenoid rim impingement in athletes: the diagnostic value of traditional radiology and magnetic resonance. Radiol Med 1994; 87:22-7.

28. Yamaguchi K, Sher JS, Andersen WK, Garretson R, Uribe JW, Hechtman K, et al. Glenohumeral motion in patients with rotator 
cuff tears: a comparison of asymptomatic and symptomatic shoulders. J Shoulder Elbow Surg 2000;9:6-11.

29. Bonutti PM, Norfray JF, Friedman RJ, Genez BM. Kinematic MRI of the shoulder. J Comput Assist Tomogr 1993;17:666-9.

30. Graichen H, Stammberger T, Bonel H, Haubner M, Englmeier $\mathrm{KH}$, Reiser M, et al. Magnetic resonance-based motion analysis of the shoulder during elevation. Clin Orthop Relat Res 2000; (370):154-63.

31. Rhoad RC, Klimkiewicz JJ, Williams GR, Kesmodel SB, Udupa JK, Kneeland JB, et al. A new in vivo technique for three-dimensional shoulder kinematics analysis. Skeletal Radiol 1998;27:92-7.

32. Shibuta H, Tamai K, Tabuchi K. Magnetic resonance imaging of the shoulder in abduction. Clin Orthop Relat Res 1998;(348): 107-13.

33. Collins RA, Gristina AG, Carter RE, Webb LX, Voytek A. Ultrasonography of the shoulder. Static and dynamic imaging. Orthop Clin North Am 1987;18:351-60.

34. Baratelli M, Cabitza P, Parrini L. Role of computerized tomography in the evaluation of the stability of the glenohumeral articulation. Radiol Med 1984;70:714-7.

35. Teyhen DS, Miller JM, Middag TR, Kane EJ. Rotator cuff fatigue and glenohumeral kinematics in participants without shoulder dysfunction. J Athl Train 2008;43:352-8.

36. Ludewig PM, Cook TM. Translations of the humerus in persons with shoulder impingement symptoms. J Orthop Sports Phys Ther 2002;32:248-59.
37. Boyer PJ, Massimini DF, Gill TJ, Papannagari R, Stewart SL, Warner JP, et al. In vivo articular cartilage contact at the glenohumeral joint: preliminary report. J Orthop Sci 2008;13:359-65.

38. Mahfouz M, Nicholson G, Komistek R, Hovis D, Kubo M. In vivo determination of the dynamics of normal, rotator cuff-deficient, total, and reverse replacement shoulders. J Bone Joint Surg Am 2005;87 Suppl 2:107-13.

39. Suero EM, Hawi N, Citak M, Decker S, Brandes J, Meller R, et al. Intraoperative imaging of the shoulder: a comparison of twoand three-dimensional imaging techniques. Technol Health Care 2015;23:171-7.

40. Baeyens JP, Van Roy P, De Schepper A, Declercq G, Clarijs JP. Glenohumeral joint kinematics related to minor anterior instability of the shoulder at the end of the late preparatory phase of throwing. Clin Biomech (Bristol, Avon) 2001;16:752-7.

41. Graichen H, Stammberger T, Bonel H, Englmeier KH, Reiser M, Eckstein F. Glenohumeral translation during active and passive elevation of the shoulder - a 3D open-MRI study. J Biomech 2000;33:609-13.

42. Paletta GA Jr, Warner JJ, Warren RF, Deutsch A, Altchek DW. Shoulder kinematics with two-plane $\mathrm{x}$-ray evaluation in patients with anterior instability or rotator cuff tearing. J Shoulder Elbow Surg 1997;6:516-27.

43. Bey MJ, Kline SK, Zauel R, Lock TR, Kolowich PA. Measuring dynamic in-vivo glenohumeral joint kinematics: technique and preliminary results. J Biomech 2008;41:711-4. 